\title{
Poisson Burr X Weibull distribution
}

\author{
T. H. M. Abouelmagd $d^{a, b, *}$, Mohammed S. Hamed ${ }^{a, b}$, Haitham M. Yousof ${ }^{b}$ \\ a Management Information System Department, Taibah University, Saudi Arabia. \\ ${ }^{b}$ Department of Statistics, Mathematics and Insurance, Benha University, Egypt.
}

\begin{abstract}
The main goal of this paper is to introduce a continuous distributions based on the zero truncated Poisson which accommodates increasing, bathtub, decreasing, J-shaped, constant and unimodal shapes of monotone failure rates. A comprehensive account of some of its mathematical properties are provided. The new probability density function can be expressed as a linear combination of exponentiated Weibull densities. The method of the maximum likelihood is used to estimate the model parameters. Empirically, we proved the importance and flexibility of the new distribution in modeling two data sets.
\end{abstract}

Keywords: Truncated Poisson, moments, maximum likelihood estimation, function, generating function.

2010 MSC: 62E05, 62F10.

(C)2019 All rights reserved.

\section{Introduction}

According to Yousof et al. [9], the cumulative distribution function (CDF) of the Burr X Weibull $(\mathrm{BrXW})$ is given as

$$
\mathrm{H}_{\mathrm{BrXW}}^{(\theta, \alpha, \beta)}(x)=\left[-\exp \left(-\left\{\exp \left[(\alpha x)^{\beta}\right]-1\right\}^{2}\right)+1\right]^{\theta}
$$

where $\theta, \beta>0$ are shape parameters. Consider the truncated Poisson (ZTP) distribution and suppose that a system has $N$ subsystems functioning independently at a given time $(t)$ where $N$ has ZTP distribution with parameter $\lambda$. The probability mass function (PMF) of $N$ can be written as

$$
\mathrm{P}_{\mathrm{ZTP}}^{(\lambda)}\left(\mathrm{N}=\left.\mathrm{n}\right|_{(\mathrm{n}=1,2, \ldots)}\right)=\lambda^{\mathrm{n}} \frac{\exp (-\lambda)}{\mathrm{n} !\{-[\exp (-\lambda)]+1\}},
$$

where for ZTP random variable $(R V)$, the expected value $\left[\mathbf{E}\left(\left.N\right|_{(\lambda)}\right)\right]$ and variance $\left[\operatorname{Var}\left(\left.N\right|_{(\lambda)}\right)\right]$ are respectively given by

$$
\mathbf{E}\left(\left.\mathrm{N}\right|_{(\lambda)}\right)=\frac{\lambda}{-[\exp (-\lambda)]+1}
$$

\footnotetext{
${ }^{*}$ Corresponding author

Email addresses: tabouelmagd@taibahu.edu.sa (T. H. M. Abouelmagd), moswilem@gmail.com (Mohammed S. Hamed), haitham . yousof@f com. bu . edu .eg (Haitham M. Yousof)
}

doi: $10.22436 /$ jnsa.012.03.05

Received: 2018-07-28 Revised: 2018-10-01 Accepted: 2018-10-06 
and

$$
\operatorname{Var}\left(\left.\mathrm{N}\right|_{(\lambda)}\right)=\frac{\lambda(1+\lambda)}{-[\exp (-\lambda)]+1}-\left(\frac{\lambda}{\{-[\exp (-\lambda)]+1\}}\right)^{2}
$$

Suppose that the failure time of each subsystem has the BrXW and let $Y_{i}$ denote the failure time of the ith subsystem and let

$$
\min \left\{Y_{1}, Y_{2}, \ldots, Y_{N}\right\}=X
$$

Then the conditional CDF of $\mathrm{X}$ given $\mathrm{N}$ can be written as

$$
\mathrm{F}(\mathrm{x} \mid \mathrm{N})=1-\operatorname{Pr}(\mathrm{X}>\mathrm{x} \mid \mathrm{N})=-\left[-\mathrm{H}_{\mathrm{BrXW}}^{(\theta, \alpha, \beta)}(\mathrm{t})+1\right]^{\mathrm{N}}+1
$$

Therefore, the unconditional CDF of the proposed model ( $\mathrm{PBrXW}$ ) density function can be expressed as (see Ramos et al. [8])

$$
\mathrm{F}_{\mathrm{PBrXW}}^{(\lambda, \theta, \alpha, \beta)}(x)=\frac{\left(1-\exp \left\{-\lambda\left[1-\exp \left(-\left\{\exp \left[(\alpha x)^{\beta}\right]-1\right\}^{2}\right)\right]^{\theta}\right\}\right)}{-[\exp (-\lambda)]+1},
$$

with the corresponding probability density function (PDF) will be

$$
\begin{aligned}
f_{\mathrm{PBrXW}}^{(\lambda, \theta, \alpha, \beta)}(x)= & 2 \theta \lambda \beta \alpha^{\beta} x^{\beta-1}[1-\exp (-\lambda)]^{-1} \exp \left[2(\alpha x)^{\beta}\right] \\
& \times \exp \left[-\left\{\exp \left[(\alpha x)^{\beta}\right]\right\}-1\right]\left\{1-\exp \left[-\left\{\exp \left[(\alpha x)^{\beta}\right]\right\}-1\right]\right\}^{\theta-1} \\
& \times\left\{1-\exp \left[-(\alpha x)^{\beta}\right]\right\} \underbrace{\exp \left(-\lambda\left\{1-\exp \left[-\left\{\exp \left[(\alpha x)^{\beta}\right]\right\}-1\right]\right\}^{\theta}\right)}_{A} .
\end{aligned}
$$

The additional parameter $(\lambda)$ induced by the new model is thought as a manner to furnish a more flexible distribution. When $\beta=2$, PBrXW reduces to $\mathrm{PBrX}$ Rayleigh (PBrXR) model, when $\beta=1, \mathrm{PBrXW}$ reduces to $\mathrm{PBrX}$ Exponential (PBrXE) model, when $\alpha=1, \mathrm{PBrXW}$ reduces to the one parameter $\mathrm{PBrXW}$ model, and when $\alpha=\beta=1, \mathrm{PBrXW}$ reduces to the new two parameter PBrXE model. The plots of the PBrXW density and HRF for some parameter values are displayed in Figures 1 and 2. From Figure 1 we note that the PDF of the new model can be can be left-skewed, right-skewed or reversed J-shape. From Figure 2 we note that the HRF of the new model can be increasing, bathtub, decreasing, J-shaped, constant, and unimodal shapes.

For other useful mixed extensions see Kuş [7], Chahkandi and Ganjali [3], Cancho et al. [2], Korkmaz et al. [5], Korkmaz and Erişoğlu [4], Ramos et al. [8], and Korkmaz et al. [6].
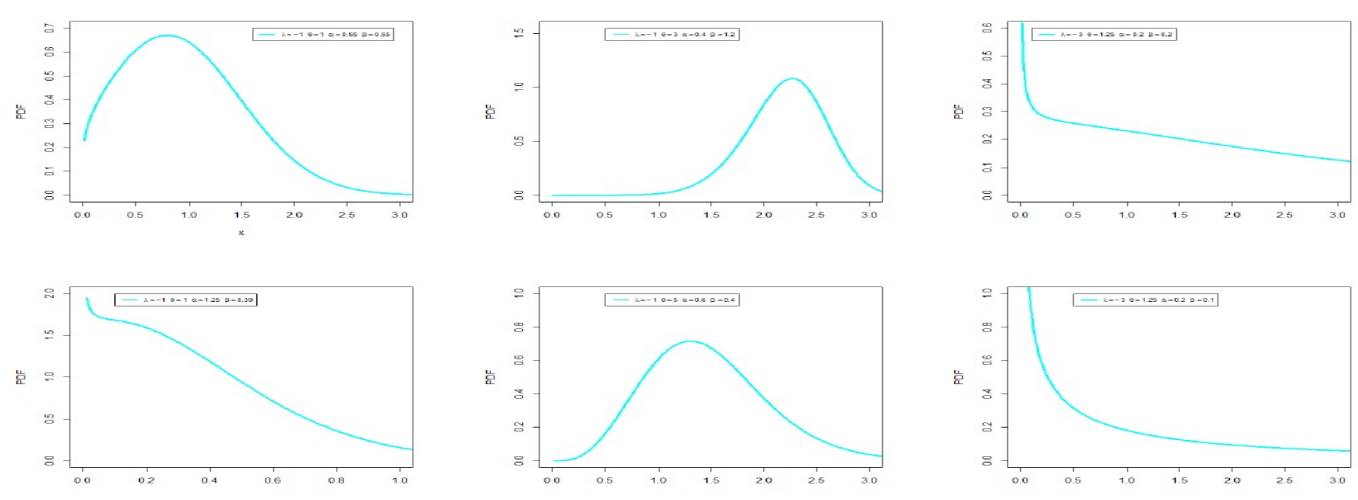

Figure 1: Plots of the PBrXW PDF for selected parameter values. 

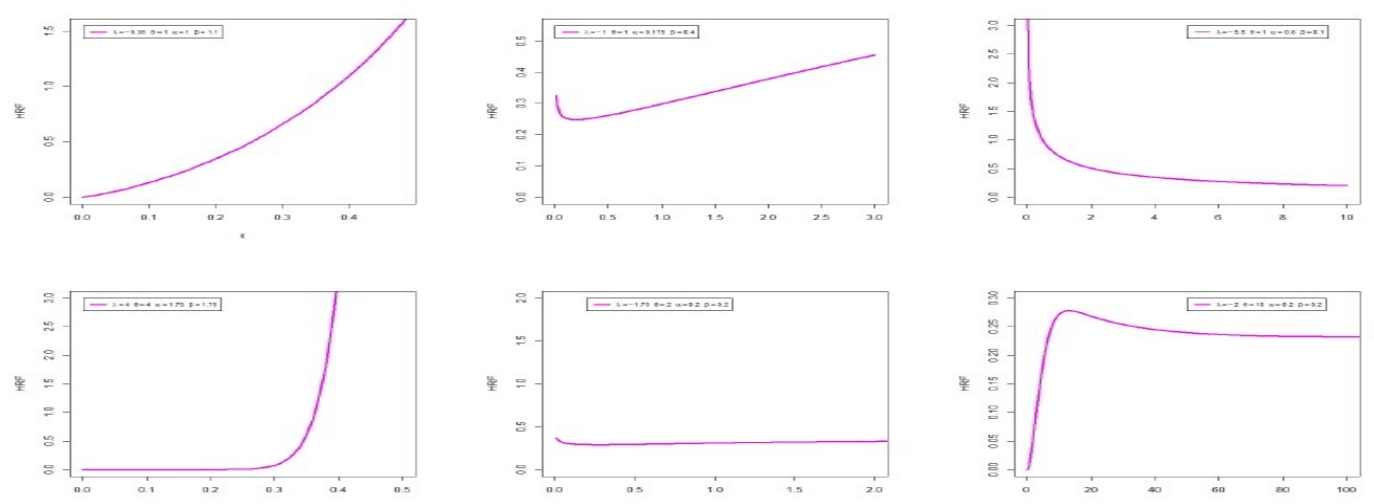

Figure 2: Plots of the PBrXW HRF for selected parameter values.

\section{Mathematical properties}

\subsection{Useful expansions}

Consider the following series

$$
\begin{aligned}
\exp (a) & =\sum_{w=0}^{\infty}\left(a^{w} / w !\right) \\
(1-\zeta)^{a-1} & =\left.\sum_{i=0}^{\infty}\left\{\left[(-1)^{i} \Gamma(a) \zeta^{i}\right] /[i ! \Gamma(a-i)]\right\}\right|_{(|\zeta|<1 \text { and } a>0 \text { is a real non-integer }),}
\end{aligned}
$$

and

$$
(1-\zeta)^{-a}=\left.\sum_{k=0}^{\infty}\left\{\left[\zeta^{k} \Gamma(a+k)\right] /[k ! \Gamma(a)]\right\}\right|_{(|\zeta|<1, a>0)} .
$$

Applying (2.1) to the quantity $A$ in (1.1), equation (1.1) becomes

$$
\begin{aligned}
\left.f_{\mathrm{PBrXW}}^{(\lambda, \theta, \alpha, \beta)}(x)\right|_{(x>0)}= & \sum_{h=0}^{\infty} \frac{2 \theta \beta \alpha^{\beta} \lambda^{1+h}(-1)^{h} x^{\beta-1}}{h ![1-\exp (-\lambda)]\left\{\exp \left[-(\alpha x)^{\beta}\right]\right\}^{3}} \\
& \times \exp \left[-\left(\exp \left[(\alpha x)^{\beta}\right]-1\right)^{2}\right]\left\{1-\left\{\exp \left[-(\alpha \mathrm{t})^{\beta}\right]\right\}\right\} \\
& \times \exp \left[-(\alpha x)^{\beta}\right] \underbrace{\left\{1-\exp \left[-\left(\exp \left[(\alpha x)^{\beta}\right]-1\right)^{2}\right]\right\}^{\theta(h+1)-1}}_{B} .
\end{aligned}
$$

Applying (2.2) to the quantity B in (2.4) we have

$$
\begin{aligned}
\left.f_{\mathrm{PBrXW}}^{(\lambda, \theta, \alpha, \beta)}(x)\right|_{(x>0)}= & \frac{2 \theta \beta \alpha^{\beta} x^{\beta-1}}{[1-\exp (-\lambda)]} \frac{\left\{1-\exp \left[-(\alpha x)^{\beta}\right]\right\}}{\left\{\exp \left[-(\alpha x)^{\beta}\right]\right\}^{3}} \\
& \times \exp \left[-(\alpha x)^{\beta}\right] \sum_{h, i=0}^{\infty} \frac{\lambda^{1+h}(-1)^{h+i} \Gamma(\theta(h+1))}{i ! \Gamma(\theta(h+1)-i)} \\
& \times \underbrace{\exp \left[-(i+1)\left(\exp \left[(\alpha x)^{\beta}\right]-1\right)^{2}\right]}_{C} .
\end{aligned}
$$


Applying (2.3) to the term C, equation (2.5) becomes

$$
\begin{aligned}
\left.f_{\operatorname{PBrXW}}^{(\lambda, \theta, \alpha, \beta)}(x)\right|_{(x>0)}= & \sum_{h, i, j=0}^{\infty} \frac{2 \theta \beta \alpha^{\beta} \lambda^{1+h}(-1)^{h+i+j}(i+1)^{j} \Gamma(\theta(h+1))}{i ! j !\left(1-e^{-\lambda}\right) \Gamma(\theta(h+1)-i)} \\
& \times x^{\beta-1} \frac{\exp \left[-(\alpha x)^{\beta}\right]\left\{1-\exp \left[-(\alpha x)^{\beta}\right]\right\}^{2 j+1}}{\left\{\exp \left[-(\alpha x)^{\beta}\right]\right\}^{2 j+3}},
\end{aligned}
$$

then we have

$$
\begin{aligned}
\left.f_{\mathrm{PBrXW}}^{(\lambda, \theta, \alpha, \beta)}(x)\right|_{(x>0)}= & \sum_{h, i, j, k=0}^{\infty} \frac{2 \theta \lambda^{1+h}(-1)^{h+i+j}(i+1)^{j}[2(1+j)+k]}{i ! j ! k ![1-\exp (-\lambda)][2(1+j)+k]} \\
& \times \beta \alpha^{\beta} x^{\beta-1} \exp \left[-(\alpha x)^{\beta}\right]\left\{1-\exp \left[-(\alpha x)^{\beta}\right]\right\}^{2 j+k+1} \frac{\Gamma(\theta(h+1)) \Gamma(3+2 j+k)}{\Gamma(\theta(h+1)-i) \Gamma(2 j+3)} .
\end{aligned}
$$

This can be written as

$$
\left.f_{\operatorname{PBrXW}}^{(\lambda, \theta, \alpha, \beta)}(x)\right|_{(x>0)}=\sum_{j, k=0}^{\infty} a_{j, k} \pi_{2(1+j)+k}(x ; \alpha, \beta),
$$

where

$$
a_{j, k}=\frac{2 \theta \lambda^{1+h}(-1)^{j} \Gamma(3+2 j+k)}{j ! k ![1-\exp (-\lambda)] \Gamma(2 j+3)[2(1+j)+k]} \sum_{h, i=0}^{\infty} \frac{(-1)^{h+i} \Gamma(\theta(h+1))(i+1)^{j}}{i ! \Gamma(\theta(h+1)-i)},
$$

and

$$
\pi_{2(1+j)+k}(x ; \alpha, \beta)=[2(1+j)+k] \beta \alpha^{\beta} x^{\beta-1}\left\{1-\exp \left[-(\alpha x)^{\beta}\right]\right\}^{2 j+k+1} \exp \left[-(\alpha x)^{\beta}\right],
$$

is the PDF of the exponentiated-W (exp-W) model with power parameter $2(1+j)+k$. Equation (2.6) reveals that the density of $X$ can be expressed as a linear mixture of exp-W density. So, several mathematical properties of the new model can be obtained by knowing those of the exp-W distribution. Similarly, the $\mathrm{CDF}$ of the PBrXW model can also be expressed as a mixture of exp-W CDF given by

$$
\left.\mathrm{F}_{\operatorname{PBrXW}}^{(\lambda, \theta, \alpha)}(x)\right|_{(x>0)}=\sum_{j, k=0}^{\infty} a_{j, k} \Pi_{2(1+j)+k}(x ; \alpha, \beta),
$$

where $\Pi_{2(1+j)+k}(x ; \alpha, \beta)$ is the CDF of the exp-W model with power parameter $2(1+j)+k$.

\subsection{Quantile spread ordering}

The quantile spread (QS), $q_{(Z)}(\omega)$, of the r.v. $X \sim \operatorname{PBrXW}(\lambda, \theta, \alpha, \beta)$ is given by

$$
q_{(Z)}(\omega)=\left.\left\{\left[F^{-1}(\omega)\right]-\left[F^{-1}(1-\omega)\right]\right\}\right|_{(\omega \in(0.5,1))},
$$

which also implies

$$
\mathbf{q}_{(Z)}(\omega)=\left[S^{-1}(1-\omega)\right]-\left[S^{-1}(\omega)\right]
$$

where

$$
\mathrm{F}^{-1}(\omega)=\mathrm{S}^{-1}(1-\omega) \text { and } \mathrm{S}(z)=1-\mathrm{F}(z),
$$

is the survival function (SF). The QS of a distribution describes how the probability mass is placed symmetrically about its median and hence can be used to formalize concepts such as peakedness and tail weight traditionally associated with kurtosis. So, it allows us to separate concepts of kurtosis and peakedness for asymmetric models. Let $Z_{1}$ and $Z_{2}$ be two random variables following the $\operatorname{PBrXW}(\lambda, \theta, \alpha, \beta)$ with 
$q_{\left(Z_{1}\right)}$ and $q_{\left(Z_{2}\right)}$, respectively. Then $Z_{1}$ is called smaller than $Z_{2}$ in quantile spread order, denoted as $Z_{1}$ $\leqslant q Z_{2}$, if

$$
q_{\left(z_{1}\right)}(\omega) \leqslant\left. q_{\left(z_{2}\right)}(\omega)\right|_{(\omega \in(0.5,1))} .
$$

The following properties of the QS order can be obtained.

1. The order $\leqslant_{q}$ is location-free

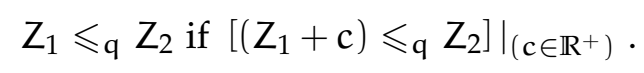

2. The order $\leqslant_{\mathrm{q}}$ is dilative

$$
Z_{1} \leqslant\left. q c Z_{1}\right|_{(c \geqslant 1)} \text { and } Z_{2} \leqslant\left. q c Z_{2}\right|_{(c \geqslant 1)} \text {. }
$$

3. Let $F_{\left(Z_{1}\right)}$ and $F_{\left(Z_{2}\right)}$ be symmetric, then

$$
Z_{1} \leqslant q Z_{2} \text { if and only if } F_{\left(Z_{1}\right)}^{-1}(\omega) \leqslant\left. F_{\left(Z_{2}\right)}^{-1}(\omega)\right|_{(\omega \in(0.5,1))} .
$$

4. The order $\leqslant_{q}$ implies ordering of the mean absolute deviation around the median, say $\left.\mathbf{j}\left(Z_{i}\right)\right|_{(i=1.2)}$,

$$
\mathbf{E}\left[\left|-\operatorname{Median}\left(Z_{1}\right)+Z_{1}\right|\right]=\mathbf{j}\left(Z_{1}\right) \text { and } \mathbf{E}\left[\left|-\operatorname{Median}\left(Z_{2}\right)+Z_{2}\right|\right]=\mathbf{\jmath}\left(Z_{2}\right),
$$

where

$$
Z_{1} \leqslant q Z_{2} \Rightarrow \mathbf{j}\left(Z_{1}\right) \leqslant q u\left(Z_{2}\right)
$$

Finally

$$
Z_{1} \leqslant q Z_{2} \text { if and only if }-Z_{1} \leqslant q-Z_{2}
$$

\subsection{Moments}

The $r^{\text {th }}$ ordinary moment of $X$, say $\mu_{r}^{\prime}$, follows from (2.6) as

$$
\mu_{r}^{\prime}=E\left(X^{r}\right)=\left.\sum_{j, k, h=0}^{\infty} C_{j, k, h}^{\{r,[2(1+j)+k]\}} \alpha^{r} \Gamma\left(1+\frac{r}{\beta}\right)\right|_{(r>-\beta),}
$$

where

and

$$
\mathbf{C}_{j, k, h}^{\{r,[2(1+j)+k]\}}=a_{j, k} \quad C_{h}^{\{r,[2(1+j)+k]\}}
$$

$$
\mathbf{C}_{m_{1}}^{\left\{r, m_{2}\right\}}=m_{2}(-1)^{m_{1}}\left(1+m_{1}\right)^{-\left(1+\frac{r}{\beta}\right)}\left(\begin{array}{c}
m_{2}-1 \\
m_{1}
\end{array}\right)
$$

Via setting $r=1,2,3$, and 4 in (2.7) we get the mean of $X, \mathbf{E}\left(X^{2}\right), \mathbf{E}\left(X^{3}\right)$, and $\mathbf{E}\left(X^{4}\right)$ as

$$
\begin{aligned}
& \mu^{\prime}=\mathbf{E}(X)=\left.\sum_{j, k, h=0}^{\infty} \mathbf{C}_{j, k, h}^{\{1,[2(1+j)+k]\}} \alpha \Gamma\left(1+\frac{1}{\beta}\right)\right|_{(1>-\beta),} \\
& \mu_{2}^{\prime}=\mathbf{E}\left(X^{2}\right)=\left.\sum_{j, k, h=0}^{\infty} C_{j, k, h}^{\{1,[2(1+j)+k]\}} \alpha^{2} \Gamma\left(1+\frac{2}{\beta}\right)\right|_{(2>-\beta),} \\
& \mu_{3}^{\prime}=\mathbf{E}\left(X^{3}\right)=\left.\sum_{j, k, h=0}^{\infty} C_{j, k, h}^{\{1,[2(1+j)+k]\}} \alpha^{3} \Gamma\left(1+\frac{3}{\beta}\right)\right|_{(3>-\beta),}
\end{aligned}
$$

and

$$
\mu_{4}^{\prime}=\mathbf{E}\left(X^{4}\right)=\left.\sum_{j, k, h=0}^{\infty} \mathbf{C}_{j, k, h}^{\{1,[2(1+j)+k]\}} \alpha^{4} \Gamma\left(1+\frac{4}{\beta}\right)\right|_{(4>-\beta)},
$$

The last four Equations can be used to get the moments about the mean, skewness, and kurtosis for the new model. 


\subsection{Incomplete moments}

The $r^{\text {th }}$ incomplete moment of $X$ is defined by $m_{r}(y)=\int_{-\infty}^{y} x^{r} f(x) d x$. We can write from (2.6)

$$
m_{r}(y)=\left.\sum_{j, k, h=0}^{\infty} C_{j, k, h}^{\{r,[2(1+j)+k]\}} \alpha^{r} \Gamma_{\left\{\left(\frac{a}{t}\right)^{\beta}\right\}}\left(1+\frac{r}{\beta}\right)\right|_{(r>-\beta)}
$$

where

$$
\Gamma_{\{z\}}(\zeta)=\gamma(\zeta, z)=\int_{0}^{z} t^{\zeta-1} \exp (-t) d t=\sum_{m=0}^{\infty}\left\{\left[(-1)^{m} z^{\zeta+m}\right] /[n !(\zeta+m)]\right\} .
$$

\subsection{Generating functions}

The moment generating function (mgf) of $X$, say $M(t)=E(\exp (t X))$, is obtained from (2.6) as

$$
M(t)=\left.\sum_{j, k, h, r=0}^{\infty} C_{j, k, h, r}^{\{r,[2(1+j)+k]\}} \alpha^{r} \Gamma\left(1+\frac{r}{\beta}\right)\right|_{(r>-\beta)},
$$

where

$$
\mathbf{C}_{j, k, h, r}^{\{r,[2(1+j)+k]\}}=\left[t^{r} / r !\right] \mathbf{C}_{j, k, h}^{\{r,[2(1+j)+k]\}} .
$$

\section{Parameter Estimation}

Let $x_{1}, \ldots, x_{n}$ be a random sample (r.s.) from $\operatorname{PBrXW}$ distribution with parameters $\lambda, \theta, \alpha$, and $\beta$. Let $\psi=(\lambda, \theta, \alpha, \beta)^{\top}$ be the $4 \times 1$ parameter vector. For determining the maximum likelihood estimators (MLEs) of $\psi$, we have the log-likelihood function

$$
\begin{aligned}
\ell=\ell(\psi)= & n \log 2+n \log \theta++n \log \beta \theta+n \beta \log \alpha \\
& -\lambda \sum_{i=1}^{n}\left\{1-\exp \left[-\left\{\exp \left[\left(\alpha x_{i}\right)^{\beta}\right]\right\}-1\right]\right\}^{\theta}+2 \sum_{i=1}^{n}\left(\alpha x_{i}\right)^{\beta} \\
& -n \log [1-\exp (-\lambda)]+(\beta-1) \log x_{i}+\sum_{i=1}^{n}\left\{1-\exp \left[-\left(\alpha x_{i}\right)^{\beta}\right]\right\} \\
& +\sum_{i=1}^{n}\left[-\left\{\exp \left[\left(\alpha x_{i}\right)^{\beta}\right]\right\}-1\right]+(\theta-1) \sum_{i=1}^{n}\left\{1-\exp \left[-\left\{\exp \left[\left(\alpha x_{i}\right)^{\beta}\right]\right\}-1\right]\right\} .
\end{aligned}
$$

The components of the score vector

$$
\mathbf{U}(\psi)=\frac{\partial}{\partial \psi} \ell(\psi)=\left(\frac{\partial}{\partial \lambda} \ell(\psi), \frac{\partial}{\partial \theta} \ell(\psi), \frac{\partial}{\partial \alpha} \ell(\psi), \frac{\partial}{\partial \beta} \ell(\psi)\right)^{\top},
$$

can be easily derived. Equation (3.1) can be maximized either directly by using the Ox program (subroutine MaxBFGS) or R (optim function) or SAS (PROC NLMIXED) or by solving the nonlinear likelihood equations obtained by differentiating (3.1). Setting the nonlinear system of equations $U_{\lambda}=0, U_{\theta}=$ $0, \mathrm{U}_{\alpha}=0$, and $\mathrm{U}_{\beta}=0$ and solving them simultaneously yields the MLE $\widehat{\psi}=(\widehat{\lambda}, \widehat{\theta}, \widehat{\alpha}, \widehat{\beta})^{\top}$.

\section{Modeling real data}

In this section, we provide three applications to show empirically the potentiality of the PBrXW model. In order to compare the fits of the $\mathrm{PBrXW}$ distribution with other competing distributions, we consider 
the Cramér-von Mises $\left(W^{\star}\right)$ and the Anderson-Darling $\left(A^{\star}\right)$ statistics. These two statistics are widely used to determine how closely a specific CDF fits the empirical distribution of a given data set. These statistics are given by

$$
W^{\star}=(1+1 / 2 n)\left[(1 / 12 n)+\sum_{j=1}^{n}\left[z_{i}-(2 j-1) / 2 n\right]^{2}\right]
$$

and

$$
A^{\star}=\left\{n+\frac{1}{n} \sum_{j=1}^{n}(2 j-1) \log \left[z_{i}\left(1-z_{n-j+1}\right)\right]\right\}\left(1+\frac{9}{4 n^{2}}+\frac{3}{4 n}\right),
$$

respectively, where $z_{i}=F\left(y_{j}\right)$ and the $y_{j}$ 's values are the ordered observations. The smaller these statistics are, the better the fit. The required computations are carried out using the $\mathrm{R}$ software. The MLEs and the corresponding standard errors (in parentheses) of the model parameters are given in Tables 1,3 , and 5. The numerical values of the statistics $W^{\star}$ and $A^{\star}$ are listed in Tables 2,4 , and 6. The histograms of the three data sets and the estimated PDFs, CDFs, and Probability- Probability (P-P) plots of the proposed model are displayed in Figures 3, 4, and 5. We shall compare the PBrXW model with other extensions of the $\mathrm{W}$ models such as the Marshall Olkin extended W (MOEW) model, the gamma W (GaW) model, the Kumaraswamy W (KwW) model, W Fréchet (WFr) model, the beta W (BW) model, the transmuted modified W (TMW) model, Kumaraswamy transmuted W (KwTW) model, the modified beta W (MBW) model, the Mcdonald W (McW) model, and the transmuted exponentiated generalized W (TExGW) model, whose PDFs are available in literature with its authors (also see Abouelmagd et al. [1]).

\subsection{Application 1: modeling failure times}

The first real data set represents the data on failure times of 84 aircraft windshield. The data are: $0.040,1.866,2.224,3.117,2.823,4.449,1.505,2.154,2.964,4.278,1.912,2.632,3.595,1.303,2.089,1.914,2.646$, $3.699,1.124,1.981,2.661,3.779,1.248,2.010,3.344,4.602,1.615,4.485,1.652,2.229,1.506,2.190,3.000,4.305$, $1.070,1.899,1.757,3.578,0.943,3.166,2.688,3.924,1.281,2.038,4.035,1.281,2.085,2.890,1.619,2.097$, $2.625,4.570,1.652,2.300,2.385,3.443,0.301,1.876,2.481,3.467,0.309,2.902,4.167,1.432,4.376,2.610,3.478$, $0.557,1.911,2.223,3.114,2.934,4.240,1.480,2.135,2.962,4.255,4.121,1.568,2.194,3.103,2.324,3.376,4.663$. Then, we will compare the fits of the PBrXW distribution with those of other competitive models whose PDFs are available in literature with its authors (see Abouelmagd et al. [1]).
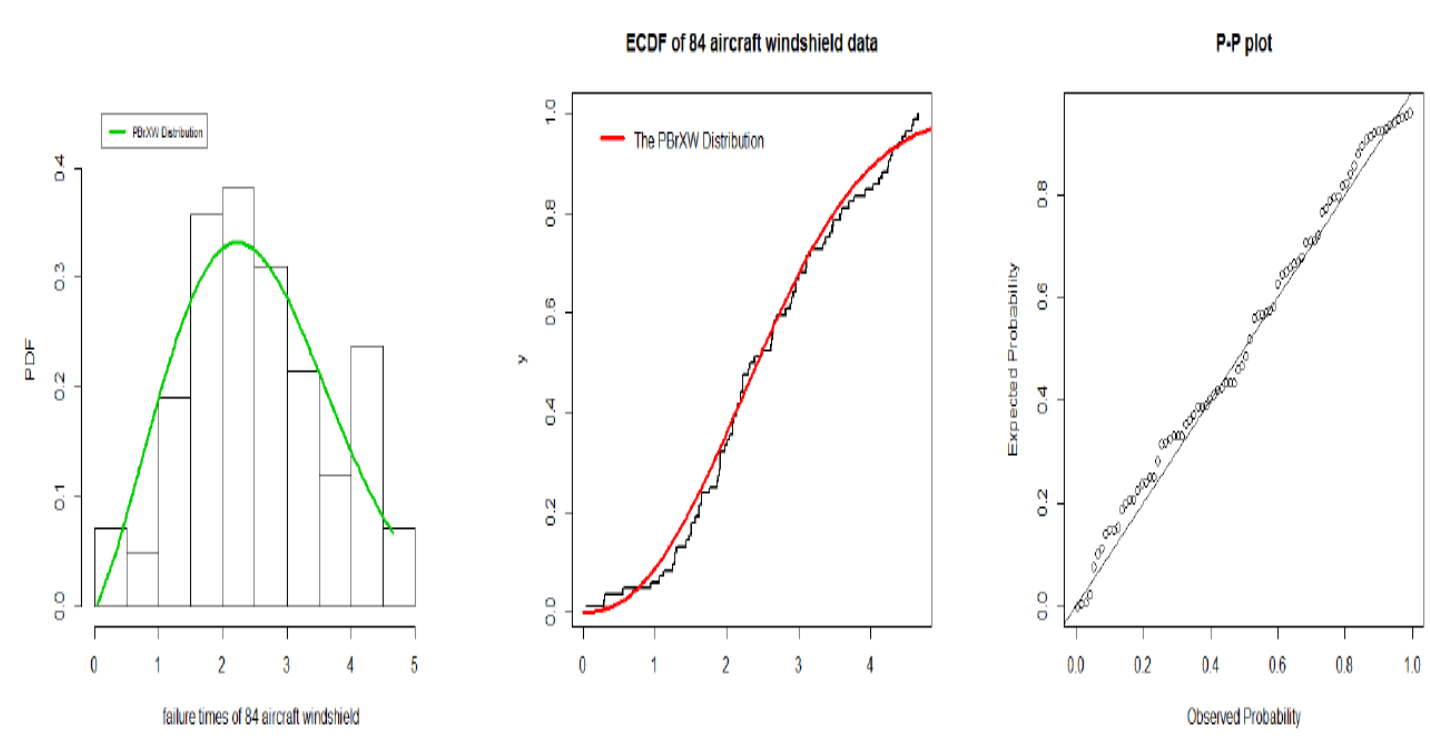

Figure 3: Estimated PDF, CDF and P-P plot for data set I. 
Table 1: MLEs (standard errors in parentheses) for aircraft windshield data.

\begin{tabular}{lccccc}
\hline Distribution & \multicolumn{5}{c}{ Estimates } \\
\hline $\operatorname{MOEW} \mid(\gamma, \beta, \alpha)$ & 488.8995 & 0.28325 & 1261.966 & \\
$\operatorname{GaW} \mid(\alpha, \beta, \gamma)$ & $(189.358)$ & $(0.013)$ & $(351.073)$ & \\
& 2.376973 & 0.8481 & 3.534401 & \\
$\operatorname{PBrXW} \mid(\lambda, \theta, \alpha, \beta)$ & $(0.378)$ & $(0.0005)$ & $(0.665)$ & \\
& -0.0277 & 1.1899 & 2.8388 & 0.4341 & \\
$\operatorname{KwW} \mid(\alpha, \beta, \mathrm{a}, \mathrm{b})$ & $1.4971)$ & $(0.7055)$ & $(1.1008)$ & $(0.096)$ & \\
& $(27.4331$ & 0.2041 & 34.6599 & 81.846 & \\
$\operatorname{WFr} \mid(\alpha, \beta, \mathrm{a}, \mathrm{b})$ & 630.9384 & $(0.042)$ & $(17.527)$ & $(52.01)$ & \\
& $(697.942)$ & $(0.032)$ & $(232.359)$ & $(0.357)$ & \\
$\operatorname{BW} \mid(\alpha, \beta, \mathrm{a}, \mathrm{b})$ & 1.36 & 0.2981 & 34.1802 & 11.496 & \\
& $(1.002)$ & $(0.06)$ & $(14.838)$ & $(6.73)$ & \\
$\operatorname{TMW} \mid(\alpha, \beta, \gamma, \lambda)$ & 0.2722 & 1 & $4.6 \times 10-6$ & 0.4685 & \\
& $(0: 014)$ & $\left(5.2 \times 10^{-5}\right)$ & $\left(1.9 \times 10^{-4}\right)$ & $(0.165)$ & \\
$\operatorname{TExGW} \mid(\alpha, \beta, \lambda, \mathrm{b})$ & 4.2567 & 0.1532 & 0.0978 & 1173.33 & \\
& $(33.401)$ & $(0: 017)$ & $(0.609)$ & $(9.792)$ & \\
$\operatorname{KWTW} \mid(\alpha, \beta, \lambda, \mathrm{a}, \mathrm{b})$ & 27.7912 & 0.178 & 0.4449 & 29.5253 & 168.060 \\
& $(33.401)$ & $(0.017)$ & $(0.609)$ & $(9.792)$ & $(129.17)$ \\
$\operatorname{MBW} \mid(\alpha, \beta, \mathrm{a}, \mathrm{b}, \mathrm{c})$ & 10.1502 & 0.1632 & 57.4167 & 19.3859 & 2.0043 \\
& $(18.697)$ & $(0.019)$ & $(14.063)$ & $(10.019)$ & $(0.662)$ \\
$\operatorname{McW} \mid(\alpha, \beta, \mathrm{a}, \mathrm{b}, \mathrm{c})$ & 1.9401 & 0.306 & 17.686 & 33.6388 & 16.7211 \\
& $(1.011)$ & $(0: 045)$ & $(6.222)$ & $(19.994)$ & $(9.722)$ \\
\hline
\end{tabular}

Table 2: $A^{\star}$ and $W^{\star}$ for data set $\mathbf{I}$.

\begin{tabular}{lcc}
\hline Distribution & $A^{\star}$ & $W^{\star}$ \\
\hline PBrXW $\mid(\lambda, \theta, \alpha, \beta)$ & $\mathbf{0 . 6 2 6 6 8}$ & $\mathbf{0 . 0 6 3 9 6}$ \\
$\operatorname{MOEW} \mid(\gamma, \beta, \alpha)$ & 4.44766 & 0.39953 \\
$\operatorname{GaW} \mid(\alpha, \beta, \gamma)$ & 1.94887 & 0.25533 \\
$\operatorname{KwW} \mid(\alpha, \beta, \mathrm{a}, \mathrm{b})$ & 1.50591 & 0.18523 \\
$\operatorname{WFr} \mid(\alpha, \beta, \mathrm{a}, \mathrm{b})$ & 1.95739 & 0.25372 \\
$\operatorname{BW} \mid(\alpha, \beta, \mathrm{a}, \mathrm{b})$ & 3.21973 & 0.46518 \\
$\operatorname{TMW} \mid(\alpha, \beta, \gamma, \lambda)$ & 11.20466 & 0.80649 \\
$\operatorname{KwTW} \mid(\alpha, \beta, \lambda, \mathrm{a}, \mathrm{b})$ & 1.36324 & 0.16401 \\
$\operatorname{MBW} \mid(\alpha, \beta, \mathrm{a}, \mathrm{b}, \mathrm{c})$ & 3.26561 & 0.47172 \\
$\operatorname{McW} \mid(\alpha, \beta, \mathrm{a}, \mathrm{b}, \mathrm{c})$ & 1.59064 & 0.1986 \\
$\operatorname{TExGW} \mid(\alpha, \beta, \lambda, \mathrm{a}, \mathrm{b})$ & 6.23321 & 1.00791 \\
\hline
\end{tabular}

Based on Table 2 and Figure 3, we conclude that the new lifetime model provides adequate fits as compared to other Weibull models with small values for $A^{\star}$ and $W^{\star}$. The proposed lifetime model is much better than the MOEW model, GaW model, KwW model, WFr model, BW model, TMW model, KwTW model, MBW model, McW model and TExGW model, and a good alternative to these models.

\subsection{Application 2: modeling remission times}

This data set represents the remission times (in months) of a random sample of 128 bladder cancer patients. This data is given by: $0.08,5.85,8.26,11.98,19.13,1.76,10.34,14.83,3.88,5.32,7.39,3.25,4.50$, 2.09, 3.48, 4.87, 0.81, 2.62,11.64, 17.36, 1.40, 3.02, 4.34, 34.26, $0.90,3.52,4.98,6.97,9.02,13.29,0.40,2.26$, $3.57,5.06,7.09,9.22,13.80,25.74,0.50,2.46,3.64,5.09,7.26,9.47,14.24,25.82,0.51,2.54,3.70,5.17,5.41$, $7.62,10.75,16.62,43.01,1.19,2.75,4.33,5.49,7.66,11.25,4.26,5.41,7.63,17.12,46.12,1.26,2.83,17.14$, $79.05,1.35,2.87,12.07,21.73,2.07,3.36,6.93,5.62,7.87,3.82,6.94,8.66,13.11,23.63,0.20,2.23,14.77,32.15$, 
$2.64,5.71,7.28,9.74,14.76,26.31,5.32,7.32,10.06,2.69,4.18,5.34,7.59,10.66,15.96,36.66,1.05,2.69$, $4.23,7.93,11.79,18.10,1.46,4.40,6.25,8.37,12.02,2.02,3.31,4.51,6.54,8.53,12.03,20.28,2.02,3.36,6.76$, $8.65,12.63,22.69$. We compare the fits of the PBrXW distribution with other competitive models like the transmuted additive Weibull distribution (TAW) and the exponentiated transmuted generalized Rayleigh (ETGR) whose PDFs are available in literature with its authors ( see Abouelmagd et al. [1]).

Table 3: MLEs (standard errors in parentheses) for the remission times data.

\begin{tabular}{llllll}
\hline Distribution & \multicolumn{5}{c}{ Estimates } \\
\hline $\mathrm{W} \mid(\alpha, \beta)$ & 9.5593 & 1.0477 & & \\
& $(0.853)$ & $(0.068)$ & & \\
$\operatorname{ETGR} \mid(\alpha, \beta, \delta, \lambda)$ & 7.3762 & 0.0473 & $0.0494,0.118$ & \\
& $(5.389)$ & $\left(3.96 \times 10^{-3}\right)$ & $(0.036),(0.26)$ & \\
$\operatorname{PBrXW} \mid(\lambda, \theta, \alpha, \beta)$ & -4.3130 & 4.8119 & 1.2414 & 0.10667 & \\
& $(2.4512)$ & $(5.02761)$ & $(0.1837)$ & $(0.0188)$ & \\
$\operatorname{TMW} \mid(\alpha, \beta, \gamma, \lambda)$ & 0.1208 & 0.8955 & 0.0002 & 0.2513 & \\
& $(0.024)$ & $(0.626)$ & $(0.011)$ & $(0.407)$ & \\
$\operatorname{MBW} \mid(\alpha, \beta, a, b, c)$ & 0.1502 & 0.1632 & 57.4167 & 19.3859 & 2.0043 \\
& $(22.437)$ & $(0.044)$ & $(37.317)$ & $(13.49)$ & $(0.789)$ \\
$\operatorname{TAW} \mid(\alpha, \beta, \gamma, \theta, \lambda)$ & 0.1139 & 0.9722 & $3.0936 \times 10^{-5}$ & 1.0065 & -0.163 \\
& $(0.032)$ & $(0.125)$ & $\left(6.106 \times 10^{-3}\right)$ & $(0.035)$ & $(0.28)$ \\
\hline
\end{tabular}

\begin{tabular}{lcc}
\multicolumn{3}{c}{ Table 4: $A^{\star}$ and $W^{\star}$ for data set II. } \\
\hline Distribution & $A^{\star}$ & $W^{\star}$ \\
\hline $\operatorname{PBrXW} \mid(\lambda, \theta, \alpha, \beta)$ & $\mathbf{0 . 1 2 4 0 8 1}$ & $\mathbf{0 . 0 1 9 2 9 8}$ \\
$\mathrm{W} \mid(\alpha, \beta)$ & 0.66279 & 0.10553 \\
$\mathrm{TMW} \mid(\alpha, \beta, \gamma, \lambda)$ & 0.76028 & 0.12511 \\
$\operatorname{MBW} \mid(\alpha, \beta, \mathrm{a}, \mathrm{b}, \mathrm{c})$ & 0.72074 & 0.10679 \\
$\mathrm{TAW} \mid(\alpha, \beta, \gamma, \theta, \lambda)$ & 0.70326 & 0.11288 \\
ETGR $\mid(\alpha, \beta, \delta, \lambda)$ & 2.36077 & 0.39794 \\
\hline
\end{tabular}
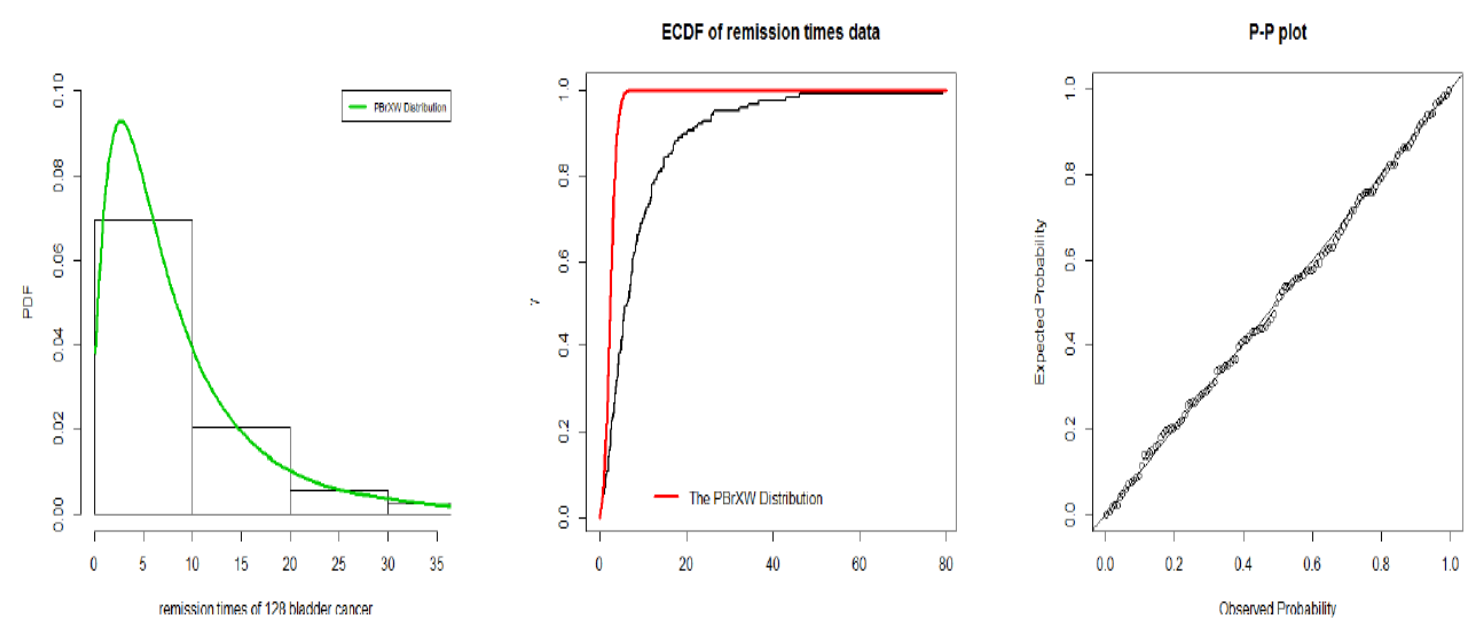

Figure 4: Estimated PDF, CDF and P-P plot for data set II.

Based on Table 4 and Figure 4 we conclude that the proposed lifetime model is much better than the W model, TMW model, MBW model, TAW model and ETGR model with small values for $A \star$ and $W^{\star}$ in modeling cancer patients data. 


\subsection{Application 3: modeling survival times}

The second real data set corresponds to the survival times (in days) of 72 guinea pigs infected with virulent tubercle bacilli. The data are: 10, 33, 44, 74, 100, 361, 402, 432, 77, 92, 93, 96, 100, 112, 102, 105, 116, $213,215,216,222,56,59,72,230,278,120,113,115,195,196,121,122,122,124,231,240,245,251,253,254$, 255, 130, 134, 136, 139, 144, 146, 153, 159, 160, 163, 163, 168, 171, 172, 176, 183, 107, 107, 108, 108, 108, 109, 197, 202, 293, 327, 342, 347, 458, 555. We shall compare the fits of the PBrXW distribution with those of other competitive models like odd WW (OWW), WW, the gamma exponentiated exponential (GaEE), W $\log \mathrm{W}(\mathrm{WLog} W)$ and exponential-exponential geometric (EEGc) distributions, whose PDFs are available in literature with its authors (see also Abouelmagd et al. [1]).

\begin{tabular}{|c|c|c|c|c|}
\hline \multirow{2}{*}{$\begin{array}{l}\text { Distribution } \\
\operatorname{BrXEW} \mid(\theta, \alpha, \beta)\end{array}$} & \multicolumn{4}{|c|}{ Estimates } \\
\hline & $\begin{array}{c}3.18 \\
(2.1174)\end{array}$ & $\begin{array}{l}5.539 \\
(2.437)\end{array}$ & $\begin{array}{l}0.166 \\
(0.0241)\end{array}$ & \\
\hline $\mathrm{WW} \mid(\beta, \gamma, \lambda)$ & $\begin{array}{c}2.6594 \\
(0.7129)\end{array}$ & $\begin{array}{l}0.693 \\
(0.1707)\end{array}$ & $\begin{array}{l}0.0270 \\
(0.0193)\end{array}$ & \\
\hline OWW $\mid(\beta, \gamma, \lambda)$ & $\begin{array}{l}11.1576 \\
(4.5449)\end{array}$ & $\begin{array}{l}0.0881 \\
(0.0355)\end{array}$ & $\begin{array}{l}0.4574 \\
(0.0770)\end{array}$ & \\
\hline $\operatorname{GaEE} \mid(\lambda, \alpha, \theta)$ & $\begin{array}{c}2.1138 \\
(1.3288)\end{array}$ & $\begin{array}{l}2.6006 \\
(0.5597)\end{array}$ & $\begin{array}{l}0.0083 \\
(0.0048)\end{array}$ & \\
\hline $\operatorname{EEGc} \mid(\alpha, \theta, p)$ & $\begin{array}{c}2.5890 \\
(0.4820)\end{array}$ & $\begin{array}{l}0.0004 \\
(0.0041)\end{array}$ & $\begin{array}{l}0.9999 \\
(0.1036)\end{array}$ & \\
\hline $\operatorname{PBrXW} \mid(\lambda, \theta, \alpha, \beta)$ & $\begin{array}{l}-13.8394 \\
(0.000)\end{array}$ & $\begin{array}{l}0.4565 \\
(0.000)\end{array}$ & $\begin{array}{l}4.0646, \\
(1.3448)\end{array}$ & $\begin{array}{l}0.14999 \\
(0.0206)\end{array}$ \\
\hline
\end{tabular}

Table 6: $A^{\star}$ and $W^{\star}$ for data set III.

\begin{tabular}{lcc}
\hline Distribution & $A^{\star}$ & $W^{\star}$ \\
\hline $\operatorname{PBrX}-W \mid(\lambda, \theta, \alpha, \beta)$ & $\mathbf{0 . 4 7 3 7}$ & $\mathbf{0 . 0 7 6 9}$ \\
$\operatorname{BrX}-\mathrm{EW} \mid(\theta, \alpha, \beta)$ & 0.5668 & 0.0907 \\
$\mathrm{~W}-\mathrm{W} \mid(\beta, \gamma, \lambda)$ & 0.7811 & 0.1427 \\
$\mathrm{OW}-\mathrm{W} \mid(\beta, \gamma, \lambda)$ & 2.4764 & 0.4494 \\
$\mathrm{GaE}-\mathrm{E} \mid(\lambda, \alpha, \theta)$ & 1.7208 & 0.3150 \\
$\mathrm{EE}-\mathrm{Gc} \mid(\alpha, \theta, p)$ & 0.5789 & 0.1047 \\
\hline
\end{tabular}
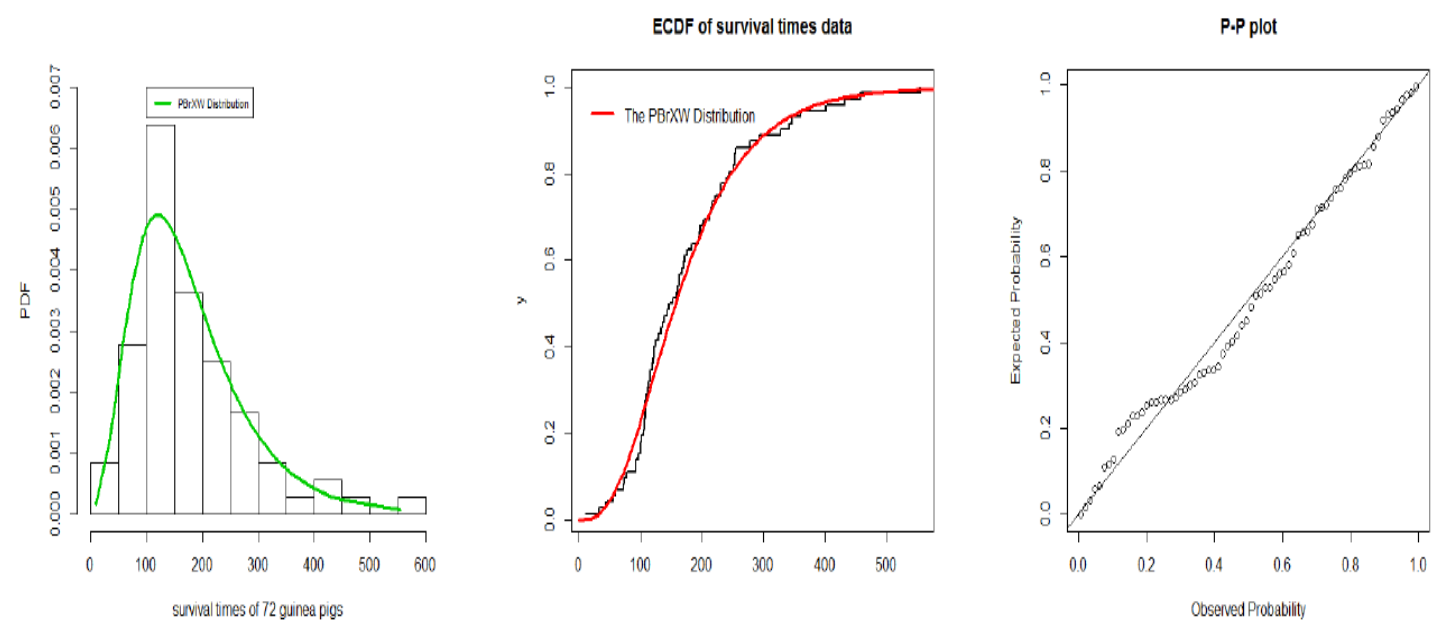

Figure 5: Estimated PDF, CDF and P-P plot for data set III. 
Based on Table 6 and Figure 5, we conclude that the proposed lifetime model is much better than the BrXEW model, WW model, OWW model, WLogW model, GaEE model and EEGc model with small values for $A^{\star}$ and $W^{\star}$ in modeling cancer patients data.

\section{Concluding remarks}

The main goal of this work is to introduce a continuous distributions based on the zero truncated Poisson which accommodates unimodal, bathtub increasing, decreasing shapes a broad variety of monotone failure rates. Some of its mathematical properties are provided. The new probability density function can be expressed as a linear combination of exponentiated Weibull density. The method of the maximum likelihood is used to estimate the model parameters. Empirically, we proved the importance and flexibility of the new distribution in modeling two data sets.

\section{References}

[1] T. H. M. Abouelmagd, A new flexible distribution based on the zero truncated Poisson distribution: mathematical properties and applications to lifetime data, Biostatistics and Biometrics, 8 (2018), 1-7. 4, 4.1, 4.2, 4.3

[2] V. G. Cancho, F. Louzada-Neto, G. D. C. Barriga, The Poisson-exponential lifetime distribution, Comput. Statist. Data Anal., 55 (2011), 677-686. 1

[3] M. Chahkandi, M. Ganjali, On some lifetime distributions with decreasing failure rate, Comput. Statist. Data Anal., 53 (2009), 4433-4440. 1

[4] M. Ç. Korkmaz, M. Erişoğlu, The Burr XII-Geometric Distribution, J. Selçuk Univer. Nat. Appl. Sci., 3 (2014), $75-87$. 1

[5] M. Ç. Korkmaz, C. Kuş, H. Erol, The mixed Weibull-negative binomial distribution, Selçuk J. Appl. Math., Special Issue (2011), 21-33. 1

[6] M. Ç. Korkmaz, H. M. Yousof, G. G. Hamedani, M. M. Ali, Marshall-Olkin Generalized G Poisson family of distributions, Pakistan J. Statist., 34 (2018), 251-267. 1

[7] C. Kuş, A new lifetime distribution, Comput. Statist. Data Anal., 51 (2007), 4497-4509. 1

[8] M. W. A. Ramos, P. R. D. Marinho, G. M. Cordeiro, R. V. da Silva, G. G. Hamedani, The Kumaraswamy-G Poisson family of distributions, J. Stat. Theory Appl., 14 (2015), 222-239. 1, 1

[9] H. M. Yousof, A. Z. Afify, G. G. Hamedani, G. Aryal, The Burr X generator of distributions for lifetime data, J. Stat. Theory Appl., 16 (2017), 288-305. 1 